\title{
1 Predation at a snail's pace. What is needed for a 2 successful hunt?
}

3 Wouterus T. M. Gruijters

5 Auckland Grammar School, 55 Mountain Road, Grafton, Auckland 1023, New Zealand

7 Running Head- Snail migration

9 Abstract: Daily observations of wild Paryphanta busbyi (New Zealand Kauri snail) along the

10 edge of a driveway were carried out for just over one year. Documented behaviours include

11 the snail's speed of movement, thrusting their heads down into leaf litter to wait in ambush for

12 prey, the daily retreat into lairs, burrowing, and the grooming of the snail's shell. The most

13 significant environmental factors affecting the presence of the snails were humidity and wind

14 direction. There was a migration of snails into and out of the observable study area at different

15 times of year. Due to the snail's pace of 1.9 to $3 \mathrm{~m} / \mathrm{hr}$ relative to its prey at $5-10 \mathrm{~m} / \mathrm{hr}$ the snails

16 would need to migrate to and inhabit areas where there is likely to be trackable prey. Overall

17 the observations indicate the hunting strategy of a periodically active ambush predator

18 sometimes based in a lair and migrating to suitably humid and windless areas as needed to

19 allow tracking of their prey.

21 Key words: Paryphanta busbyi, Gastropoda Rhytidae, Kauri snail, pupurangi, predator,

22 humidity, wind, earthworm, tracking, lair, migration. 


\section{Introduction}

25 Paryphanta busbyi (Mollusca: Gastropoda: Rhytididae: Paryphantinae), commonly known as

26 a kauri snail or pupurangi in Maori, is a large carnivorous land snail found in the northern part

27 of the North Island of New Zealand (Fig. 1). Due to restricted distribution, nocturnal habits,

28 protected conservation status and rarity, studies on the snail are infrequent. A one paragraph

29 description of a preserved specimen was done by Hutton (1881) and in more detail by

30 Murdoch (1903). Further studies established a phylogeny partly related to their distribution

31 with a species recovery plan in mind (Powell 1946, Parrish 1992, Parrish et al. 1995). Spencer

32 et al (2006) resolved phylogeny using mDNA COI sequences and despite latent

33 morphological debate around two recognised subspecies $P$. busbyi watti and $P$. busbyi busbyi

34 we accept Spencer's phylogeny which does not distinguish them. Harmonic radar tracking of

35 the snails developed by Lovei et al. 1997 helped answer some of the basic questions about the

36 snail's movements and biology with studies by Stringer \& Montefiore (2000), Stringer et al.

37 (2002), and Stringer et al. (2003).

38 Studies of movements of $P$. busbyi using harmonic radar to relocate individual snails required recapture to confirm their presence and identities (Stringer \& Montefiore 2000; Stringer et al. 2003). From the 126 snails included in Stringer et al.'s 2003 study insights into life history such as reproduction and mortality were gained. Their observations show the description of

42 behaviours averaged over 126 individuals. The current study involves daily observations on a

43 smaller number of snails, attempting to fill some behavioural gaps left in previous studies by

44 long intervals between observations. Frequent observations meant minimizing the disturbance

45 of the snails and their habitat had to be a priority for this study. It was hypothesised this

46 approach would allow information to be gathered on $P$. busbyi that would elucidate some new aspects of the snail's behaviour and put those already discovered into a better context. 


\section{Study site}

51 The population of snails studied resided in the Woodlands Park, Waitakere ranges, Auckland,

52 North Island, New Zealand (36 57' 42.82"S, 174 37' 10.38"E) (Fig.1).

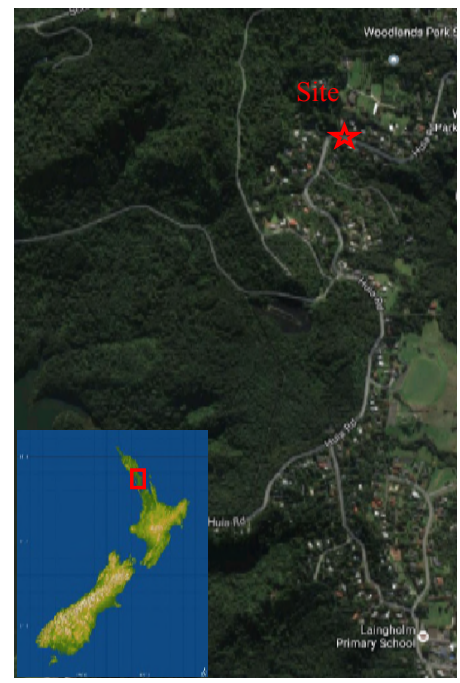

53 Fig. 1. Map of New Zealand showing the location of the study between park and low density

54 suburbia.

55 The area was originally covered in temperate rainforest with mixed podocarp species, but was

56 logged of nearly all large trees about 90 years or more prior to the study, leaving a few remnants of larger decaying unidentifiable stumps and log pieces. Attempts to convert the areas to farmland further altered the vegetation, which has now been regenerating for about 62 years. Grazing by brushtail possums (Trichosurus vulpecula) has resulted in the regeneration to a dominant canopy of kanuka (Kunzea ericoides). While some larger pururi (Vitex lucens), totara (Podocarpus totara), rimu (Dacrydium cupressinum) and other species were left by loggers, most are currently small in stature. Temperatures in the area range from $6^{\circ} \mathrm{C}$ on a cold winter night to 22.5 or in microenvironments $28^{\circ} \mathrm{C}$ on a hot summer day. Frosts only occur in winter in localised exposed areas of ground, not among the trees. Rainfall is highly variable depending on local geography with no localized rain gauge. The nearest monitored rain gauge is just under $2000 \mathrm{~m}$ away indicates rainfall is in the order of $2000 \mathrm{~mm} / \mathrm{yr}$ in the area the snails were located.

68 More particular to the study area we have surroundings that form part of the eastern side of a north-south ridge. Snails were located and observed when they appeared in a shallow trench next to or more rarely on a 33.5 meters long stretch of exposed aggregate driveway. The trench is approximately $300 \mathrm{~mm}$ wide, between 0 to $220 \mathrm{~mm}$ deep originally for draining a 
72 small bush clad mainly south facing $30 \mathrm{~m}$ long slope along $23 \mathrm{~m}$ of the driveway's length. The drain did not show an observable depth of water along its length during the year-long study.

74 The only water observed was trickle fed from overhanging vegetation though during prolonged downpours it is likely to have more. On rare occasions snails were observed on much larger area of the driveway itself or on the opposite side of the driveway which has no formed channel and drops away down the hillside. Tunnels appeared periodically under the driveway.

\section{Daily snail observations}

In order to know how often to observe the snail's behaviour an indication of their speed of movement in the wild had to be determined. Speed in the context of snails in this paper is the time it took for a snail to cover a known distance without knowing if the snail moved continuously or intermittently. Even when the snail is videoed moving apparently continuously it is possible the snail's mechanism of movement involved stopping and starting an unperceived number of times. The methodology used is not intended to elucidate the mechanism of movement but rather the overall distance covered over a period of time during different activities. Intermittent starting and stopping was easily perceptible during behaviours such as hunting or sensing the environment and may be more intuitively thought of as the snail's pace for undertaking particular activities. The pace of most snails was established by revisiting snails over periods of minutes or sometimes hours and measuring their change in position using a measuring tape to determine how far the centre of the snail's whorl had moved. For example, in the case of a $55 \mathrm{~mm}$ snail we took a video on a hand-held Nokia RM978 phone with default automatic settings to determine speed. To determine the snail's speed in the absence of the observer two still photographs were taken at a defined interval and the distance moved measured. Searching for snails was done at least once a day during darkness using a red head light and occasionally during the day when the snails very rarely active. A total of 374 of the 377 days had at least one inspection. There is an unquantified bias towards observing larger snails as these are much easier to see and find. In at least 72 cases follow up inspections of discovered snails was done the same night to determine behaviours. Red light was used during night time photography. Measurements were done using a measuring tape without making contact with the snail. Avoiding contact of the measuring tape with the snail meant that most snail size measurements were within $5 \mathrm{~mm}$. Snails that were moving in a single direction would have 
104 their speed recorded by taking repeated measurements over minutes to hours depending on

105 their speed, terrain and the ability to find the snail again without disturbing their habitat. For

106 the purpose of this study snails were distinguished by their differing shell sizes and relative

107 locations. Finding two snails of the same size on the same night only occurred once during the

108 entire study and this pair were within $100 \mathrm{~mm}$ of each other and small enough to be freshly

109 hatched from the same nest. Smaller snails were more easily lost than larger ones as

110 displacing the leaf litter in which they moved to relocate them was considered disturbing the

111 environment. A mirror or endoscope were necessary to see or photograph within most lairs.

112 Sometimes more than a few seconds of exposure to red or white light could cause snails to

113 begin retracting into their shells though this behaviour varied in a similar way to that

114 described for earthworm prey retracting into burrows (Darwin 1881). There were some longer

115 duration observations (30min) but these were generally avoided as they might alter the wild

116 snail's natural behaviour more than is necessary for the study. Most observations of snails

117 lasted only long enough to establish where snails were, what they were doing and to allow

118 taking of the occasional photographs. 


\section{Results}

\section{Determining a snail's pace}

121 The most documented example of determining an adult snail's speed was a rare daylight

122 sighting on the $21^{\text {st }}$ of July 2015 at 8:08 am. A 60mm snail was filmed using a hand-held

123 Nokia RM978 phone with default automatic settings. The video lasting $1 \mathrm{~min} 11 \mathrm{sec}$ may be

124 viewed at:

125 https://plus.google.com/u/0/photos/116507430608150673768/albums/6181306159640899073

$126 / 6181306164563221042$. The terrain being transited was a sloped artificial concrete surface of

127 exposed red aggregate. At the time of filming abrupt breaks in the cloud brought increased

128 light levels during an otherwise dark dawn. The snail moved towards an area containing lairs

129 and leaf litter many centimetres deep. Approaching the snail more closely than about a meter

130 led to increased movement of eye stalks and tentacles including their partial retraction, a

131 similar response to that seen at times to snails illuminated with red LED light during night

132 time filming. Filming positions of the camera which gave this response were avoided where

133 possible.

134 Measurements of the shift of the centre of the snail spiral during the period of the video taken

135 at 8:08am on the 21 st July 2015 when the snail moved approximately 0.02 meters was

136 consistent with a snail's pace of between 0.9 to 1.1 meters per hour. Two still photos taken at

137 8:31 am and 8:40 am showed the centre of the spiral shell moved 0.27 meters, giving an

138 approximate speed of 1.9 meters per hour. There was no observable slime trail. Another snail

139 of a similar size was measured at night travelling near the same place as the former snail a

140 year later at a speed of $2.9 \mathrm{~m} /$ hour. These are considered travelling speeds on a relatively

141 regular substrate with lesser speeds in leaf litter noted at other times later in this paper.

\section{A Selected short term observation}

143 To help the reader interpret snail behaviours indicated in the year-long study a short period of

144 the study is considered first in some detail. In fig. 2 a $42 \mathrm{~mm}$ snail was first observed on the

145 night of the $6^{\text {th }}$ of October 2015 and moved as indicated on the y axis. Circumstances meant

146 that this $42 \mathrm{~mm}$ snail was active and able to be tracked on more consecutive nights than any

147 other snail. The movements seen in fig. 2 are consistent with the types of movements seen by

148 other snails tracked over shorter periods during the rest of the year. 


\section{Movement of snails 6 Oct to 10 Nov 2015}

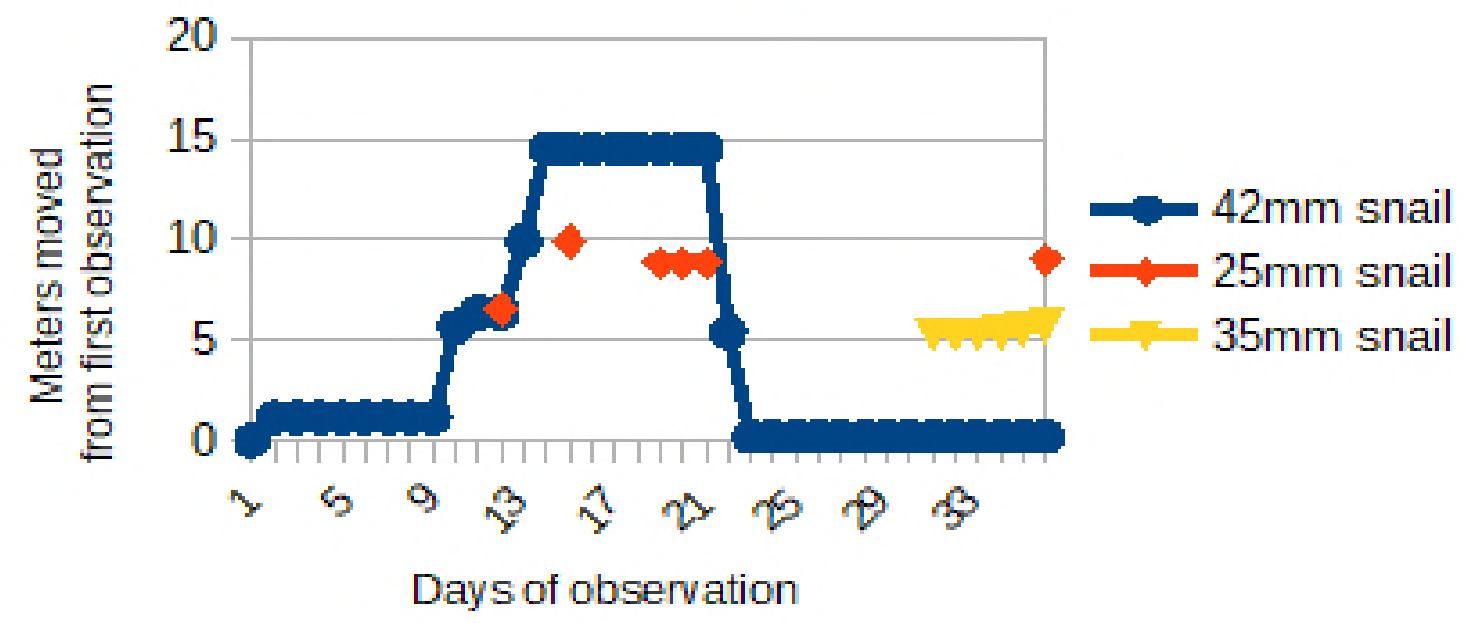

150 Fig. 2. The distance moved in meters 3 snails from 6 October to $28^{\text {th }}$ October 2015 with the 151 data accrued from 179 inspections over the 45 days.

152 During night time observation on day 1 the $42 \mathrm{~mm}$ snail would appear to be hunting in deep

153 leaf litter. It would move at rates of 0.5 to $1.5 \mathrm{~m}$ per hour. While hunting the snail would wave 154 its eye stalks and tentacles, pausing frequently and sometimes thrusting its head down into the 155 deep leaf litter in any one spot for more than 10 minutes at a time (Fig. 3).

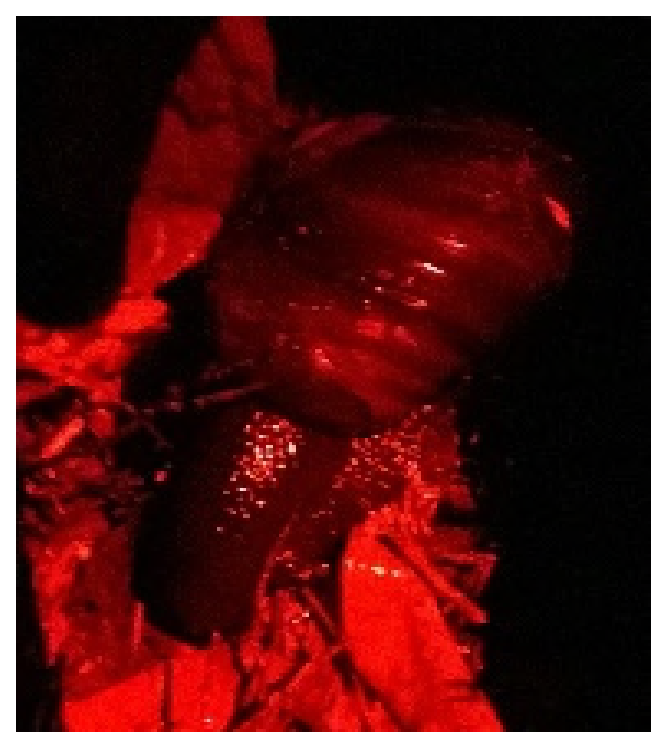

156 Fig. 3 Snail photographed under red light from above. The head and neck are below the leaf

157 litter curving downward away from the viewer with the shell and foot remaining at the leaf

158 litter surface.

159 In this mode the snail moved about $170 \mathrm{~mm}$ over 2 hours from approximately 22:15 to 01:00. 
160 By dawn the snail had moved into a lair $1.14 \mathrm{~m}$ from its original position. As indicated in fig.

1612 by the horizontal graph lines the snail was observed in the lair day and night for days at a

162 time. Repeated observations within the lairs showed the body partially extended towards the

163 entrance of the lair, with eye stalks and tentacles sometimes extended, other times with the

164 head retracted into the extended body. During daylight of day one the snail was seen probing

165 the floor of the lair with its tentacles and also reaching up to probe the ceiling in a similar

166 manner. The snail sometimes moved further towards the back or far left of the lair making it

167 difficult to observe. While other snails observed in lairs were at time retracted into their shells

168 it was clear that this snail was not retracted into its shell at any of the dozen or more times it

169 was seen in the first lair it entered, even when the snail was motionless for prolonged periods.

170 To summarise the activity within the lair the snail was sometimes stationary facing the front

171 of the lair, sometimes mobile and sometimes less observable towards the back or not visible at

172 all.

173 The snail was observed intermittently near the entrance of the first lair until day 6. Daily and

174 nightly searches and lack of disturbance of obstacles put at the lair's entrance indicated the

175 snail did not emerge from the lair until day 8 after significant rain. All indications were that

176 the snail remained in the lair for nine days though we cannot completely rule out short,

177 unobserved forays outside the lair. When the snail was finally found outside the lair on day 9

178 it had moved 5.5 meters from the lairs entrance in the 6 hours since the previous search,

179 indicating a pace under $1 \mathrm{~m} / \mathrm{hr}$. Observing the snail for half an hour while it appeared to

180 search for prey showed 0.3 meters of linear movement, indicating a pace while hunting of 0.6

$181 \mathrm{~m} / \mathrm{hr}$.

182 Other snails shown on the graph would also at times raise their heads well above the substrate

183 they were traversing, moving the head from side to side while waving their tentacles. They

184 may also leave a lair for a few hours and then return the same night. The snails often appeared

185 to be scanning the environment; sensing the air for food, moisture or some other airborne

186 factor. Having paused to sense the environment they would then resume their travels or stay in

187 the lair. In fig. 3 consecutive horizontal graph points usually indicates the snails being in a

188 lair. Only a couple of snails in the year of study were observed in the same place on

189 consecutive nights when outside a lair. The snails at times returned to a similar position within

190 a lair after each night's activity, often to within millimetres, indicating some ability to

191 navigate. 
192 Other than the commonly observed behaviours of sensing, travelling, hunting and residing in

193 lairs there were more rarely observed behaviours interpreted here as burrowing (Fig $411^{\text {th }}$ Oct

194 2016), climbing branches (Fig 59 May 2016 10:10pm) and maintaining the shell exterior (Fig

$195612^{\text {th }}$ August 2016).

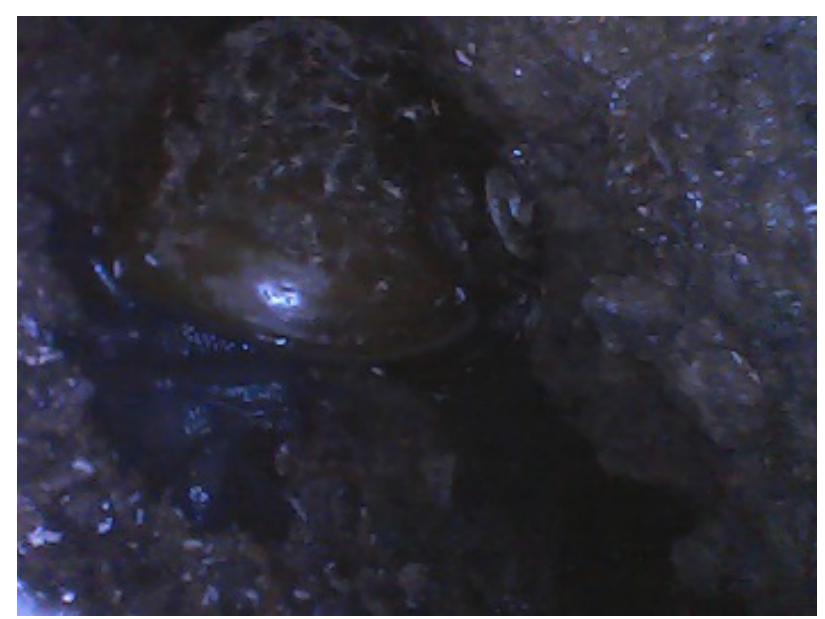

196 Fig. 4 A snail burrowing photographed using an endoscope inserted into a lair. Mud is on the

197 shell from where soil had contacted it. The tail is facing the viewer and appears wrinkled,

198 perhaps as part of the burrowing action as it tries for force its way deeper.

199

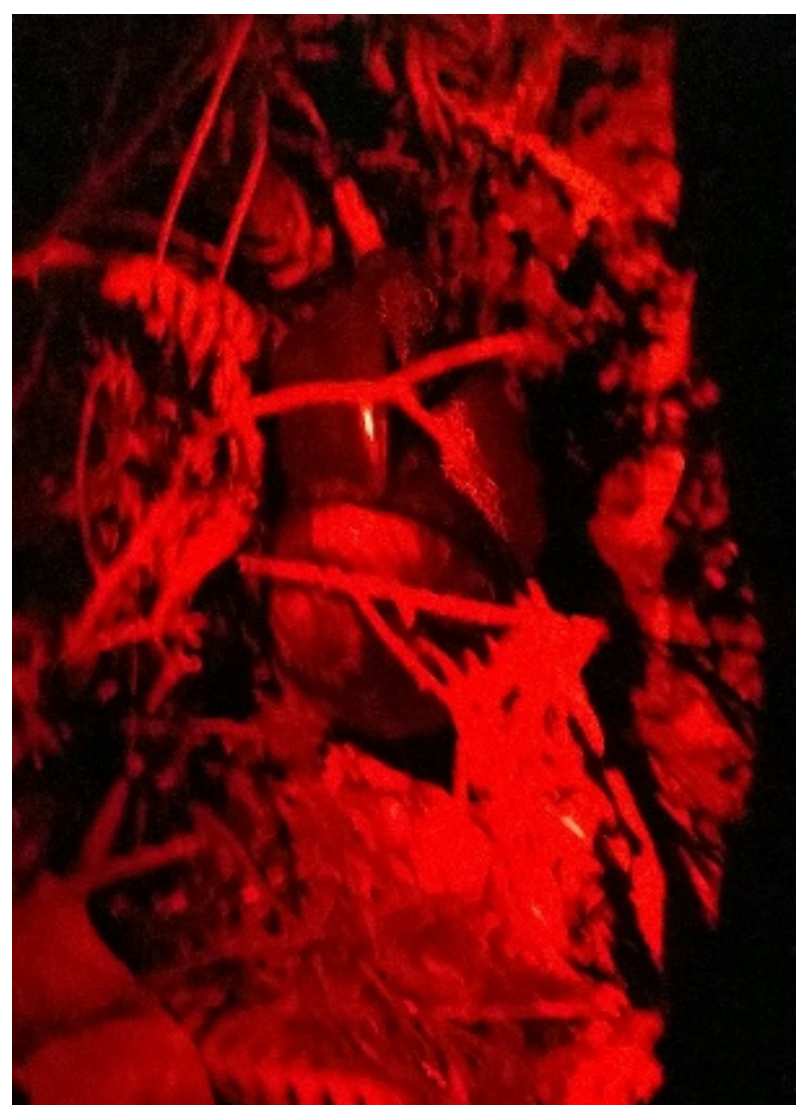

200 Fig. 5 Snail climbing nearly vertically up a twig much narrower than the body of the animal. 
201 The back of the foot folded forward onto itself, wrapped around the twig. Snails climbing out

202 of the study area on steep soil could fall backwards on lose soil. The stick apparently gives

203 more reliable traction.

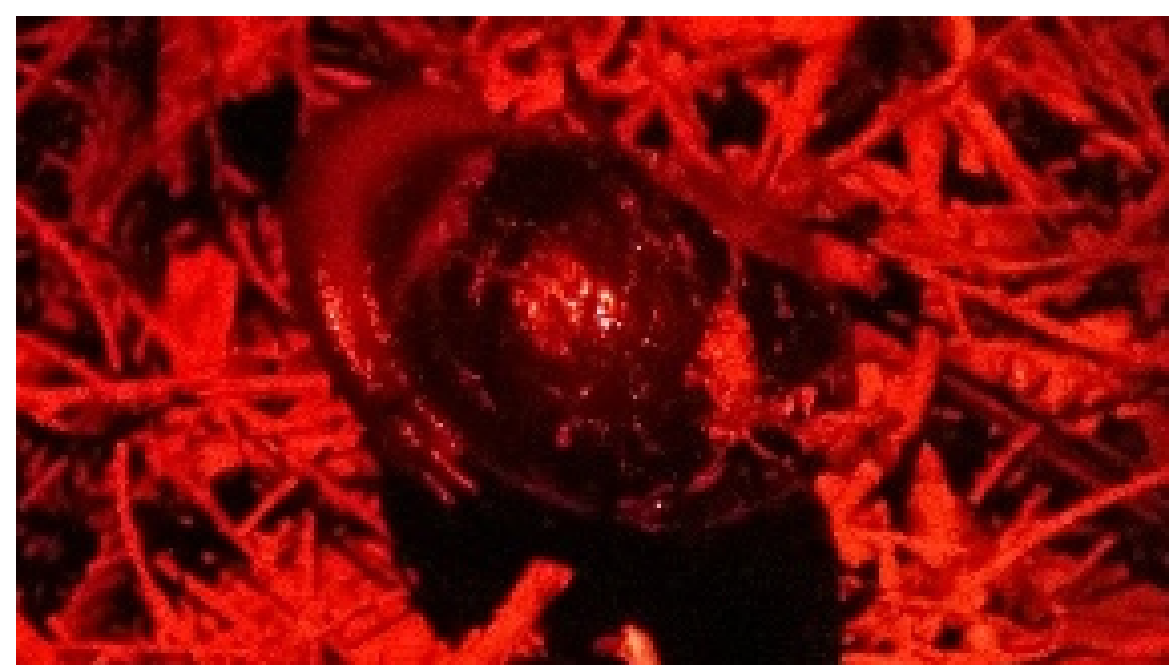

205 Fig. 6 Snail with the head wrapped backwards over the shell. The shell appears to be covered 206 in debris of some sort.

\section{Longer term daily observations}

208 Data was collected for 372 days over a 377 day period with a total of 786 visits to the study area. The nine snails being plotted in fig. 7 is likely to under-represent the total number in the soil trench as the habitat was not destructively searched.

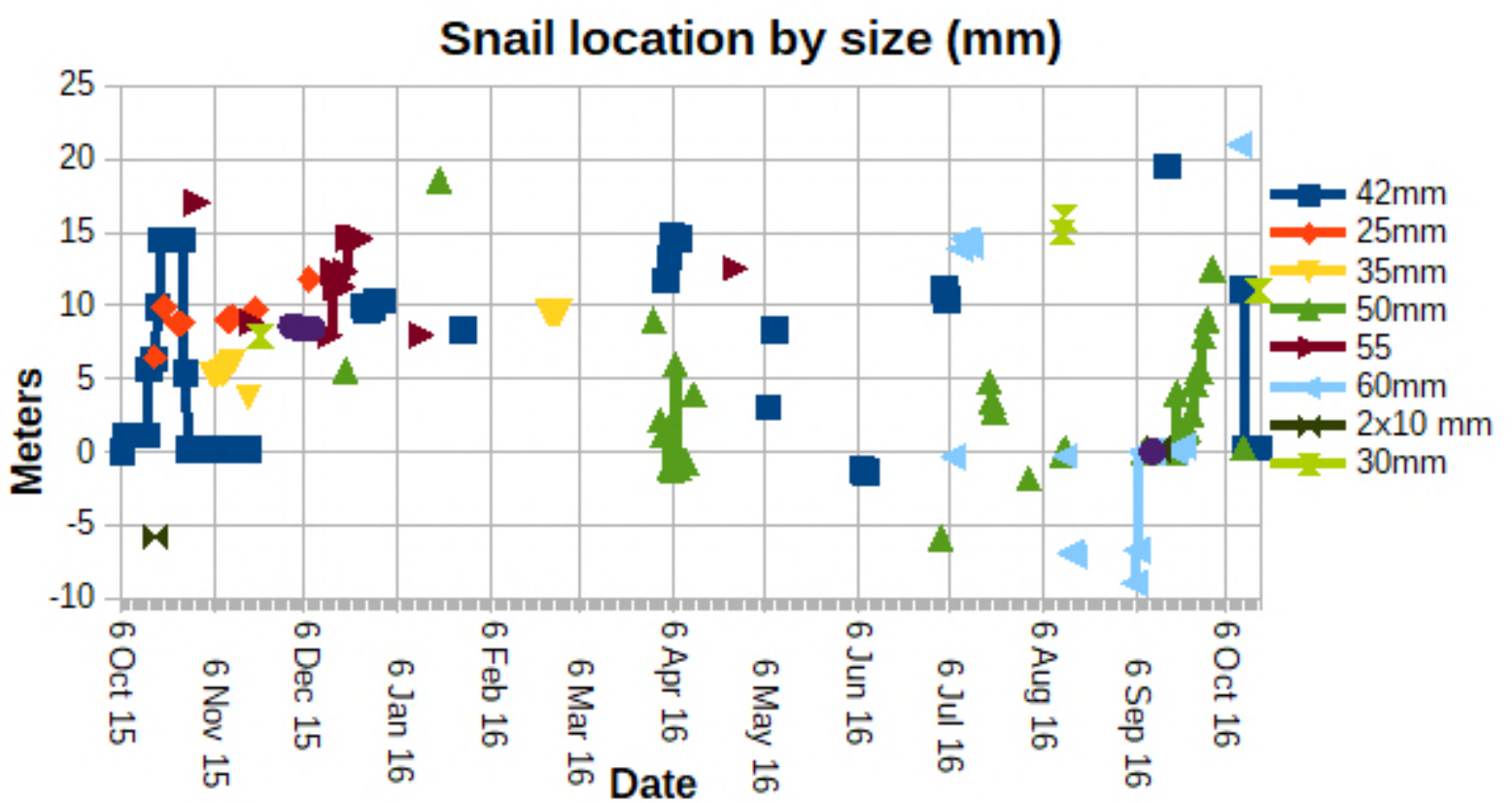


$12 / 08 / 18$

Page 11

213 different times of the year. Where the lines connect the points the snail was observed

214 frequently enough for the observer to ensure it is the same snail rather than just the same

215 sized snail.

216 Over 372 days snails were observed on 191 days with 612 separate sightings recorded. Of the

217191 days snails were observed they were in lairs on 100 days and outside lairs on 72 days. On

21819 days they were observed at different times both inside and outside lairs or somewhere in

219 between. The most common behaviours of no movement, sensing the air, travelling and

220 hunting were difficult to define and are not quantified.

221 The data used to produce fig. 7 was elucidated further using Fisher Exact (P) tests suitable for 222 rarer events as the snail number appearing on any one day were often 0 or 1 . Comparing snail 223 presence against local weather station data $1.73 \mathrm{~km}$ away revealed significant correlations. The 224 most significant factors were humidity (negative correlation $\mathrm{P}=0.000004359$ ) and south west 225 wind direction ( 150 to 200 degrees $\mathrm{P}=0.003784$ ). There is an easily observable positive 226 correlation in fig. 8 indicating numbers of snails being higher from the beginning of spring to 227 the summer solstice and backed up by Fisher exact value $\mathrm{P}<0.0000001$ comparing that period 228 with the year as a whole. In summer and autumn the situation reverses (negative correlation $\mathrm{P}=0.00000369)$. Rainfall $(\mathrm{P}=0.4114)$ showed no significant correlation, with temperature

$230 \quad(\mathrm{P}=0.3113)$ and wind speed $(\mathrm{P}=0.2280)$ showing little more. Winter also shows no significant 231 correlation with snail presence (negative correlation $\mathrm{P}=0.2692$ ).

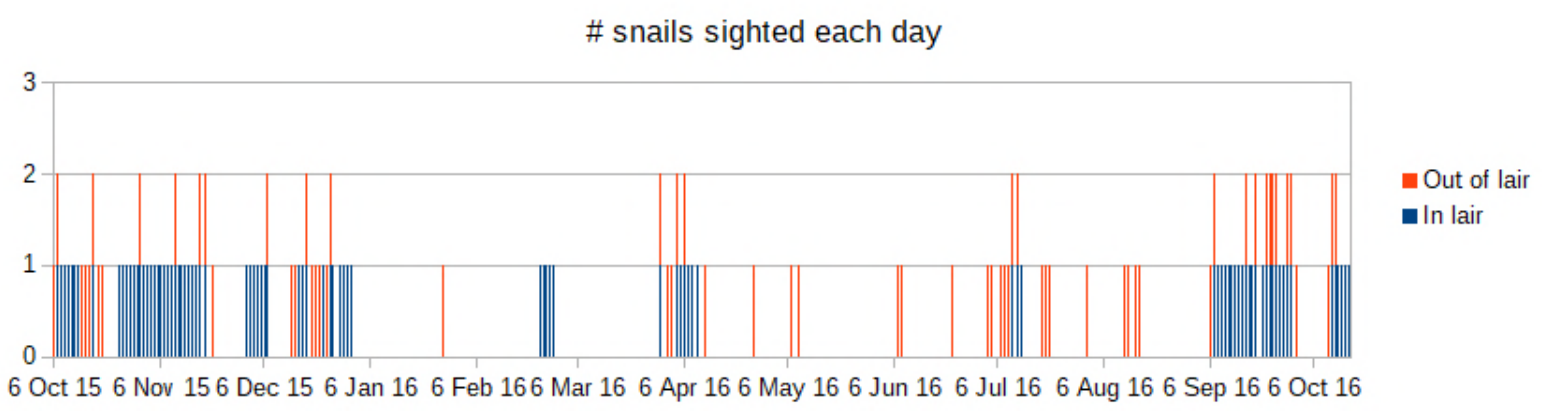

233 Fig. 8 The number of observed snails in the study area was patchy over the course of the year,

234 with numbers dropping to zero for weeks at a time over the driest and to a lesser degree

235 wetter months. While there is apparently a small peak of activity near the beginning of each

236 season the greatest activity is from early spring to the summer solstice. 


\section{Discussion}

239 Observations of wild P. busbyi for prolonged periods without disturbing the snails or the

240 environment proved difficult. It is likely that snails in the study area were simply hidden too

241 far underground or in the leaf litter to be observed. Despite this limitation it is reasonable to

242 believe that at some time during the year the snails in the study area spend significant time

243 underground day and night (fig.8). Lairs are at times used as a base with the snail leaving and

244 returning to the same lair during a single night. At other times snails leave one lair for

245 another. The significance of this newly observed behaviour may be speculated upon with

246 possibilities including avoiding predators, avoiding light, or seeking areas of higher humidity.

247 Underground environments chosen by the snails may attract suitable prey items and so allow

248 daytime ambush of prey while the snails remain concealed. The ability to move between lairs

249 is limited by the snail's pace. If lairs are too far apart the snail may have to stay above ground

250 during the day before reaching another lair. A maximum observed speed during this particular

251 study of $2.9 \mathrm{~m}$ per hour is more than the $2 \mathrm{~m}$ per hour recorded in captivity for a similar

252 carnivorous snail Powelliphanta traversi traversi (Devine 1997). There is no observable slime

253 trail in P. busbyi. Slime trails are found in other snails which have been recorded moving at

254 greater speeds e.g. garden snail at 3.5 to 5.4 meters per hour (Pavlova 2001, Mckee et al.

255 2013). In areas with suitable lairs greater than around 20m meters apart snails would be forced

256 to spend time above ground during the day even if lairs are preferred. The ease with which

257 smaller snails could find the smaller lairs may explain why they are difficult to relocate after

258 being observed at the surface. Lair utilisation and burrowing would also explain the very low success rate in re-locating snails with harmonic radar as the radar does not penetrate the

260 ground well (Lovei et al 1997, Stringer et al 2003). Any protection from predators snails

261 might gain from using lairs may influence how large snails could grow as larger predators

262 would more easily access the larger lair entrances larger snails would require to accommodate 263 their shells.

264 Other behaviours of the snails observed included climbing branches much smaller in diameter

265 than the animal itself while ascending steeper inclines, burrowing and the snail apparently

266 maintaining the outside of its shell when it became dirty. While these activities may be

267 expected and perhaps already observed by others they are documented via photographs here

268 for Paraphanta busbyi.

269 Statistical analysis correlating snail activity with weather over the study period revealed the 
$12 / 08 / 18$

270 greatest significance of humidity followed by wind direction. The simplest hypothesis

271 consistent with the humidity data is that the snails are present and most active in the study

272 area when the humidity is lowest leading to the idea that the snails may prefer dry conditions.

273 Such a hypothesis is easily refuted by the nature of the study area where the snails' are

274 preferring a trench with lairs on the south side of a hill where it is wetter than the

275 surroundings the trench is acting as a drain for. The more likely valid hypothesis we will work

276 with is that the drain is a humid, sheltered area preferred by the snails during periods of lower

277 humidity outside the study area. A similar preference for humid conditions has been shown by

278 another carnivorous snail (Roda et al 2016). The second slightly lesser correlation with wind

279 direction is also consistent with the later hypothesis as on days the wind comes from the

280 southeast the study area is not sheltered from the wind by the hill and no correlation with snail

281 presence was found (Fisher Exact $\mathrm{P}=0.3502$ ). South easterly winds funnelled up the valley

282 will lead to greater agitation of the air in the study area causing the usually still and damp air

283 trapped by the vegetation to become less humid. South-westerly winds in contrast seemed to

284 correlate with snail presence (Fisher Exact $\mathrm{P}=0.003784$ ) and this was also the direction of the

285 main ridge in the area which acts as a barrier to the wind. The preference snails are showing

286 for windless and humid conditions may be attributable to a generalization that molluscs prefer

287 such environments. Snails can be used as indicators of soil humidity Čejka et al (2009) and

288 different coloured snails of the same species may even respond differently to the same

289 humidity Abdel-Rehim (2008). The ability for carnivorous snails to track prey more

290 successfully in humid and windless conditions may play a role in this study. Having done the uncontrolled experiment of dropping an earthworm near the front of a snail and watching the reaction it is clear that, for minutes after the worm had "got away" straight past the snail and into a crevice the snail did a slow $U$ turn and followed the path of the worm at a fraction of the worm's speed. With the worm having disappeared down a crevice many minutes ago the snail eventually reached the crevice and forced itself as far as its shell would allow into the narrow gap the earthworm had entered. The snail stayed there for at least an hour, presumably waiting for the worm's return. This demonstrable ability to track prey requires a systematic study of its own but would help explain why windless and humid air is preferred by the snails as such conditions would aid their ability to track prey and occupy good ambush positions. When trying to locate earthworms it may also be that the snail is using the strategy of finding areas where the preferred food of the earthworms is present. Earthworms themselves use smell to locate their food (Zirbes et al 2011) so it would be reasonable to hypothesis their predator 
303 does the same when trying to locate them. Another reason for the snails to visit the site is the 304 requirement for calcium for the shell (Sulikowska-Drozd et al 2007). The driveway adjacent 305 to the drain may be appealing to the snails as the aggregate used for concrete contained a few 306 shell fragments as it is mined from a small island. No attempt was made to quantify this effect 307 in the current study.

308 According to Lovei et al (1997) a P. busbyi snails ranged over about $1000 \mathrm{~m}^{2}$ during 2.5 years 309 with the intervals of relocation varying from 6 to 16 weeks and displacements up to $25 \mathrm{~m}$ from 310 the most frequented area. It is unclear in the paper why the interval between relocations was 311 so large and why only 1 of the 37 snails was relocated with that frequency. Similar limitations 312 occurred in a much larger study by Stringer et al (2003) with 126 snails found and 93 fitted 313 with transponders but the median recapture was 3 times over 26 field trips. They began their 314 discussion "Many of our data are preliminary because we found and followed few of these 315 rare snails and because of the long periods between observations". From the current study it is 316 worthwhile considering why the radar studies were problematic for recapture of the snails.

317 This study shows the snails often frequent damp, humid, underground environments. Lovie et 318 al (1997) noted "Water (also humidity) attenuated the signal." of the radar with ground penetration of around $100 \mathrm{~mm}$. Snails more than $100 \mathrm{~mm}$ underground may be hidden from the radar. In the current study snails were located with an endoscope up to $300 \mathrm{~mm}$ into lairs and a

321 large live snail was dug up 500mm below ground level in soil with high organic content in 322 another site nearby (Kevin Barker, personal communication). With a measured snail's pace in 323 the current study of over $2 \mathrm{~m} / \mathrm{hr}$ and winter nights of over 12 hours $24 \mathrm{~m}$ could be covered by a 324 snail in one night. The long period between observations of months in other studies is 325 therefore unlikely to give a reasonable representation of the snails range as there is ample time 326 for snails to leave the area detectable by the radar and return again. From the data collected 327 (Fig. 7) it appears the study site is being used on consecutive nights and by multiple snails per 328 night as the bush starts to dry up at the beginning of spring until the summer sets in at the 329 solstice. The snail's preference for windless humid environments is clearly supported by the 330 data and the study area is preferred at least in part for those reasons. The importance of 331 humidity is hinted at by Stringer and Montefiore (2000) by showing a significant correlation 332 between snail numbers and altitude. While not directly showing a correlation with humidity 333 they noted cloud cover associated with the hill tops. We may postulate that snails not 334 locatable in a study area may bury themselves deeper underground or they may leave the 
335 study area all together or they may do both. While not statistically defined snails have been observed leaving our study area. One was tracked for over $10 \mathrm{~m}$ heading in a straight line away

337 from the study site. Another was tracked a similar distance heading into the site. Fig. 5 was

338 taken of a snail as it attempted to climb north out of the study site trench. During longer periods of no snail sightings an endoscope was used to search as deep into the lairs as possible most often without success in the mostly shallow lairs. It is reasonable to conclude the snails are moving in and out of the area as it becomes more or less appealing relative to the surroundings. This would make sense in terms of following their earthworm prey which are also known to migrate (Mather \& Christensen 1992).

344 Lair based activity in windless humid environments has important implications for conservation strategies in the forest types studied here (Walker 2003). Ideal areas would require not only prey but year round high humidity, shade, minimal wind, the opportunity to burrow and good lairs to establish a thriving population. Such repopulation of suitable bush areas is unlikely to happen from what we know of their dispersal. It may well be that extinct birds such as the many varieties of Moa aided the snail's dispersal to fragmented favourable areas in the past in a similar way that birds currently distribute other snails (Kazuto et al. 2008; Kramarenko 2014; Wada et al. 2014). Large Moa may have eaten snails whole with some passing through the digestive tract alive and so be deposited into new areas in their faeces. People can also act as good agents for dispersal (Gerber and Clark 2015). To prevent extinction of $P$. busbyi (IUCN red list: lower risk/near threatened) and other endangered snails qualified people may need to take an active role in assisting snails to colonize suitable new areas at speeds greater than a snail's pace.

\section{Conclusion}

Paryphtanta busbyi appear to be a very active predator moving at up to $2.9 \mathrm{~m} / \mathrm{hr}$ when travelling. Where lairs are present they may be used continuously for days at a time. When conditions are less suitable elsewhere the snails migrate to areas of a higher humidity and little wind, conditions that favour tracking their prey by smell. Such migrations lead to localized peaks in snail numbers and activity. With discontinuous studies these migrations may have led to miscalculations around the size of territories and estimates of population numbers. The ability of adult snails to spread to new areas is limited by their speed, quite specific environmental needs for hunting and lack of a known natural dispersal mechanism. 


\section{References}

368 Abdel-Rehim AH. (2008) The effects of temperature and humidity on the nocturnal activity of different shell colour morphs of the land snail Arianta arbustorum. Biol. J of the Linnean Soc. 20 (4):385-395

Baily S.E.R. (1989) Foraging behaviour of terrestrial gastropods: integrating field and laboratory. J. Mollus. Stud. 55 (2):263-272.

373 Čejka T, Hamerlik L (2009) Land snails as indicators of soil humidity in Danubian woodland 374 (SW Slovakia). Polish Journal of Ecology 57 (4), 741-747

375 Darwin C (1881). The formation of vegetable mould through the action of worms with 376 observations on their habits. John Murray edition by David Price, First Edition, October $10^{\text {th }}$, 3771881.

378 Devine CD 1997. Some aspects of behaviour and ecology of the land snail Powelliphanta traversi traversi Powell (Rhytididae: Rhytidinae). Masters Thesis. Massey University. Gerber J, Clark S.A. First record of the predatory land snail Streptostele (Tomostele) musaecola (Pulmonata: Streptaxidae) in the continental United States. American

382 Conchologist 43, No. 4, 26-28

383 Hutton FW 1881. Notes on some pulmonate Mollusca. Trans. Proc. N.Z. Inst. 14: 150-158 2 384 plates.

385 Kazuto K, Shinichiro W, Satoshi C 2008. Possible dispersal of land snails by birds. Ornithol. 386 Sci. 7, 167-171.

387 Kramarenko S (2014). Active and passive dispersal of terrestrial mollusks: a review.

388 Ruthenica 24.

389 Lovei G, Stringer I, Devine C, Cartellieri M 1997. The harmonic radar-a method using 390 inexpensive tags to study invertebrate movement on land. N. Z. J. Ecol. 21, 187-193.

391 Mather JG, Christensen O 1992. Surface migration of earthworms in grassland. Pedobiologia $39236,51-57$.

393 Murdoch R 1903. On the Anatomy of Paryphanta busbyi, Gray. Trans NZ Inst xiv, 258-262.

394 Mckee A, Voltzow J, Pernet B (2013).Substrate Attributes Determine Gait in a Terrestrial 395 Gastropod. Biol. Bull. 224: 53-61.

396 Parrish R 1992. Paryphanta busbyi watti survey (Department of Conservation).

397 Parrish R, Sherley G, Aviss M. Giant land snail recovery plan Placostylus spp., Paryphanta 398 Spp., (Wellington: Department of Conservation Threatened Species Unit). 
$12 / 08 / 18$

Page 17

399 Pavlova G.A. 2001. Effects of serotonin, dopamine and ergometrine on locomotion in the

400 pulmonate mollusc Helix lucorum". J. of Exp. Biol. 204 (9), 1625-1633.

401 Powell A. 1946. The Paryphantidae of New Zealand. No. 5. Further new species of

402 Paryphanta, Wainuia and Rhytida. 3, 137-144.

403 Roda A, Nachman G, Weihman S, Yong Cong M, Zimmerman F (2016) Reproductive

404 Ecology of the Giant African Snail in South Florida: Implications for Eradication Programs.

405 PLoS ONE 11(11): e0165408. https://doi.org/10.1371/journal.pone.0165408

406 Spencer H, Brook F, Kennedy M 2006. Phylogeny of Kauri Snails and their allies from

407 Northland, New Zealand (Mollusca: Gastropoda: Rhytididae: Paryphantinae). Mol.

408 Phylogenet. Evol. 38, 835-842.

409 Stringer I, Montefiore R 2000. Distribution and biology of the endangered Kauri snail,

410 Paryphanta busbyi watti. Sci. Conserv. 163, 42pp.

411 Stringer I, McLean M, Arnold G, Bassett S, Montefore R 2002. Growth and development of

412 the rare land snail Paryphanta busbyi watti (Pulmonata: Rhytididae). Moll Res 22, 203-220.

413 Stringer I, Bassett S, McLean M, McCartney J, Parrish G 2003. Biology and Conservation of

414 the rare New Zealand land snail Paryphanta busbyi watti (Mollusca, Pulmonata). Invertebr.

415 Biol. 122, 241-251.

416 Sulikowska-Drozd A, Horsák M 2007. Sulikowska-Drozd, A. \& Horsák, M. Biologia (2007)

417 62: 201. https://doi.org/10.2478/s11756-007-0030-7

418 Tomiyama, K. and Nakane, M 1993. Dispersal patterns of the giant African snail, Achatina

419 fulica (Ferussac)(Stylommatophora: Achatinidae), equipped with a radio-transmitter. J. of

420 Mollusc. Studies, 59(3), 315-322.

421 Wada S, Kawakami K, Chiba S 2014. Snails can survive passage through a bird's digestive

422 system. J. Biogeogr. 39, 69-73.

423 Walker K 2003. Recovery Plans for Powelliphanta Land Snails (Wellington: Department of

424 Conservation).

425 Zirbes L, Mescher M, Vrancken V, Wathelet J, Verheggen F, Thonart P, Haubruge E 2011.

426 Earthworms use odor cues to locate and feed on microorganisms in soil. PLoS ONE 6(7):

427 e21927. doi:10.1371/journal.pone.0021927 